\title{
ANTIMICROBIAL SUSCEPTIBILITY AMONG ENTEROCOCCUS ISOLATES FROM THE CITY OF PORTO ALEGRE, RS, BRAZIL
}

\section{Pedro Alves d'Azevedo" ${ }^{1 *}$; Cícero Armídio Gomes Dias ${ }^{1}$; Sibele Krebs Lemos²; José Augusto Ferreira Bittencourt²; Lúcia Martins Teixeira ${ }^{3}$}

\author{
${ }^{1}$ Departamento de Microbiologia e Parasitologia, Fundação Faculdade Federal de Ciências Médicas de Porto Alegre, \\ Porto Alegre, RS, Brasil. ${ }^{2}$ Estudantes de Iniciação Científica, Fundação de Amparo a Pesquisa do Estado do \\ Rio Grande do Sul, Porto Alegre, RS, Brasil. ${ }^{3}$ Instituto de Microbiologia da Universidade Federal do Rio de Janeiro, \\ Rio de Janeiro, RJ, Brasil
}

Submitted: January 14, 2004 ; Returned to authors for corrections: April 22, 2004; Approved: August 18, 2004

\begin{abstract}
Resistance to several classes of antimicrobial agents is a remarkable characteristic of enterococcal strains increasingly reported worldwide. Information about strains isolated in the southern region of Brazil is still limited. In this study, a total of 455 consecutive enterococcal isolates recovered from patients living in Porto Alegre, Brazil, were identified at species level and evaluated for their antimicrobial susceptibilities by agar diffusion testing. The most frequent species was E. faecalis (92.8\%), followed by E. faecium (2.9\%), E. gallinarum (1.5\%), E. avium (1.1\%), E. hirae (0.7\%), E. casseliflavus (0.4\%), E. durans (0.4\%), and E. raffinosus $(0.2 \%)$. According to the results of disk tests $62.0 \%$ of the strains were resistant to tetracycline, $42.6 \%$ to erythromycin, $24.8 \%$ to chloramphenicol, $22.6 \%$ to ciprofloxacin, $22.0 \%$ to norfloxacin, $3.5 \%$ to ampicillin, $3.5 \%$ to nitrofurantoin. High level resistance to aminoglycosides was found in $37.8 \%$ of the isolates, with $23.5 \%$ being resistant to gentamicin, $14.3 \%$ to streptomycin, and $2.8 \%$ to both gentamicin and streptomycin. No vancomycin resistant or b-lactamase producing isolates were found. The results indicate that a significant percentage of isolates are resistant to different antimicrobials, pointing out the need for control strategies to avoid dissemination of resistant isolates and for continuous surveillance for the detection of emerging resistance traits.
\end{abstract}

Key-words: enterococcal, antimicrobial susceptibility, resistance

\section{INTRODUCTION}

The infections caused by enterococci are a major issue in hospital settings $(7,25,29)$. These microorganisms are innately more resistant to many of the antimicrobials used in hospitals, something which provides them some selective advantage $(24,25)$. Surveys carried out in the United States show that enterococci are the second leading microorganism among those causing surgical infections and nosocomial infections of the urinary tract, and the third among those causing hospital infections in general $(7,29)$.
Although enterococci are part of the normal microbiota of the gastrointestinal and genitourinary tracts $(6,24)$, they can lead to various infections such as those of the urinary tract, bacteremias, endocarditis and infections of wounds, among others $(24,25)$.

An important characteristic of this genus is the higher resistance to antimicrobials, which has created difficulties in the treatment of infections. These microorganisms show intrinsic resistance to several therapeutic drugs such as penicillins, cephalosporins, aminoglycosides, and clindamycin (21). Thus, the effectiveness of the treatment of severe infections by

*Corresponding author. Mailing address: Fundação Faculdade Federal de Ciências Médicas de Porto Alegre, Rua Sarmento Leite, 245/211. 90050-170, Porto Alegre, RS, Brasil. Tel.: (+5551) 224-8822. Fax: (+5551) 226-9756. E-mail: pedroaze@ fffcmpa.tche.br 
enterococci normally depends on the synergistic bactericidal effect provided by the combination of an active agent against the cell wall, such as a $\beta$-lactamic or a glycopeptide, and an aminoglycoside (11). Although the enterococci are relatively resistant to aminoglycosides, the combination of an aminoglycoside with penicillin, ampicillin or a glycopeptide has resulted in a valuable bactericidal synergistic effect (11). However, the prevalence of enterococcal resistance to one or more of these antibiotics is increasing and creating serious therapeutic difficulties $(11,17)$. In addition, isolates of enterococci that are resistant to multiple antimicrobial agents, including aminoglycosides, beta-lactamics, and vancomycin, have been reported worldwide $(16,19,20,24)$. Also, they can fairly easily develop resistance to tetracyclines, chloramphenicol, and erythromycin (22). The phenotypes of resistance which are clinically considered as more significant are those associated with high level resistance to aminoglycosides (HLR-A), resistance to $\beta$-lactamics and to glycopeptides.

The purpose of this study was to identify enterococcal species isolated from various clinical materials in 5 hospitals in the city of Porto Alegre, and to characterize them with respect to their susceptibility to antimicrobials.

\section{MATERIALS AND METHODS}

\section{Bacterial Isolates}

A total of 455 isolates of enterococci isolated from various clinical materials (community and nosocomial sources) were investigated. The isolates belong to the collection of the Fundação Faculdade Federal de Ciências Médicas de Porto Alegre, RS, and were collected in five health institutions located in Porto Alegre, namely: Irmandade Santa Casa de Misericórdia de Porto Alegre (ISCMPA, general public hospital), Hospital de Clínicas de Porto Alegre (HCPA, school hospital), Hospital da Criança Santo Antônio (HCSA, children hospital), Hospital de Pronto Socorro de Porto Alegre (HPS, emergency healthcare), and Laboratório Weinmann (LW, private laboratory). The following standard strains were also used for quality control purposes: Enterococcus avium SS-559, Enterococcus casseliflavus SS-1229, Enterococcus durans SS-661, Enterococcus faecalis SS-1273, E. faecalis ATCC 29212, Enterococcus faecium SS-1274, Enterococcus gallinarum SS-1228, Enterococcus hirae SS-1227, and Enterococcus raffinosus $\mathrm{SS}-1278$. The isolates were kept as suspensions in a solution containing 10\% (p/v) skim milk (Nestlé, Araçatuba, SP, Brasil) and $10 \%$ (v/v) glycerol, maintained frozen at $-20^{\circ} \mathrm{C}$ in glass flasks with screw lids.

\section{Identification}

The purity of each isolate was verified through culture in Brain Heart Infusion Agar (BHI agar, DIFCO Laboratories, Detroit, MI, EUA) plus 5\% (v/v) defibrinated lamb blood and $24 \mathrm{~h}$ incubation at $35^{\circ} \mathrm{C}$. For species identification, the isolates were submitted to standard tests according to Facklam, Sahm and Teixeira (6).

\section{Determination of antimicrobial susceptibility - Agar diffusion testing}

Antimicrobial susceptibility was evaluated through agar diffusion tests performed according to the guidelines of the National Committee for Clinical Laboratory Standards (26) using disks impregnated with high levels of gentamicin $(120 \mu \mathrm{g})$ and streptomycin $(300 \mu \mathrm{g})$ and standard disks of the following antimicrobials: ampicillin, ciprofloxacin, chloramphenicol, erythromycin, nitrofurantoin, norfloxacin, tetracycline and vancomycin (CECON, Centro de Controle e Produtos para Diagnóstico Ltda, São Paulo, SP, Brazil).

The reading and interpretation of the breakpoints were done according to the NCCLS guidelines (26). Strain E. faecalis ATCC 29212 was used as control in these tests.

\section{Test for detection of $\boldsymbol{\beta}$-lactamase production}

The isolates were tested for production of $\beta$-lactamase using disks containing cefinase (Nitrocefin, Oxoid, Basingstoke, Hampshire, England). Staphylococcus aureus ATCC 29213 and ATCC 25923 were used as positive and negative controls, respectively.

\section{Statistical analysis}

The chi-square test was used to compare differences between proportions using the EPI-INFO software, version 2002. Results with $\mathrm{p}<0.05$ were considered as significant.

\section{RESULTS}

The 455 enterococcal isolates investigated were identified as follows: $422(92.8 \%)$ E. faecalis, $13(2.9 \%)$ E. faecium, $7(1.5 \%)$ E. gallinarum, $5(1.1 \%)$ E. avium, $3(0.7 \%)$ E. hirae, $2(0.4 \%)$ E. casseliflavus, $2(0.4 \%)$ E. durans, and $1(0.2 \%)$ E. raffinosus (Table 1).

Table 2 presents the source of the 455 enterococcal isolates, showing that most of them were isolated from urine $(320 ; 70.3 \%)$, followed by secretions $(94 ; 20.7 \%)$, blood $(12 ; 2.6 \%)$, catheter end $(11 ; 2.4 \%)$, and other materials $(18 ; 4 \%)$. HCPA was the institution with the greatest number of isolates from urine, while the ISCMPA was the one with the greatest number of isolates from secretions.

Table 3 shows the distribution of the different enterococcal species according to the isolation source. The species $E$. faecalis (310 isolates) and E. faecium (8 isolates) were the ones most frequently isolated from urine. Most isolates of the less frequent species were not isolated from urine $(10 \%)$ but from other sources, such as secretions $(45 \%)$.

According to the results of the diffusion tests (Table 4), $62.0 \%$ of the isolates were resistant to tetracycline, $42.6 \%$ to 
Table 1. Species distribution among 455 Enterococcus isolates from patients in 5 healthcare institutions in the city of Porto Alegre, Brazil.

\begin{tabular}{lrrrrrc}
\hline & \multicolumn{5}{c}{ Healthcare Institution $^{1}$} \\
\cline { 2 - 7 } \multicolumn{1}{c}{ Species } & ISCMPA & HCPA & HCSA & HPS & LW & Total (\%) \\
\hline E. faecalis & $\mathbf{1 9 5}$ & $\mathbf{2 0 6}$ & $\mathbf{1 3}$ & $\mathbf{7}$ & $\mathbf{1}$ & $\mathbf{4 2 2}(\mathbf{9 2 . 8})$ \\
E. faecium & 2 & 10 & 1 & 0 & 0 & $13(2.9)$ \\
E. gallinarum & 2 & 5 & 0 & 0 & 0 & $7(1.5)$ \\
E. avium & 0 & 3 & 0 & 1 & 1 & $5(1.1)$ \\
E. hirae & 1 & 2 & 0 & 0 & 0 & $3(0.7)$ \\
E. casseliflavus & 1 & 0 & 0 & 1 & 0 & $2(0.4)$ \\
E. durans & 0 & 1 & 0 & 1 & 0 & $2(0.4)$ \\
E. raffinosus & 0 & 1 & 0 & 0 & 0 & $1(0.2)$ \\
\hline Total & $\mathbf{2 0 1}$ & $\mathbf{2 2 8}$ & $\mathbf{1 4}$ & $\mathbf{1 0}$ & $\mathbf{2}$ & $\mathbf{4 5 5}(\mathbf{1 0 0})$ \\
\hline
\end{tabular}

${ }^{1}$ ISCMPA, Irmandade Santa Casa de Misericórdia de Porto Alegre; HCPA, Hospital de Clínicas de Porto Alegre; HCSA, Hospital da Criança Santo Antônio; HPS, Hospital de Pronto Socorro de Porto Alegre; LW, Laboratório Weinmann.

erythromycin, $24.8 \%$ to chloramphenicol, $22.6 \%$ to ciprofloxacin, $22.0 \%$ to norfloxacin, $3.5 \%$ to ampicillin, and $3.5 \%$ to nitrofurantoin. High level resistance to aminoglycosides (HLRA) was found in $37.8 \%$ of the isolates, with $23.5 \%$ being resistant to gentamicin and $14.3 \%$ to streptomycin. Concomitant resistance to gentamicin and streptomycin was detected in $2.8 \%$ of the isolates. No isolates with full resistance to vancomycin were found, and none of the isolates produced $\beta$-lactamase.

\section{DISCUSSION}

The distribution of species according to isolation sources, observed in this study, was similar to what was previously found by other authors in different areas $(8,18,19,27)$, with a predominance of isolation of E. faecalis $(92.8 \%)$ and E. faecium (2.9\%), and urine $(70.3 \%)$ and various secretions $(20.7 \%)$ as the
Table 2. Isolation sources of 455 Enterococcus isolates from patients in 5 healthcare institutions in the city of Porto Alegre, Brazil.

\begin{tabular}{lrrrrrc}
\hline & \multicolumn{5}{c}{ Healthcare Institution $^{1}$} \\
\cline { 2 - 7 } \multicolumn{1}{c}{ Species } & ISCMPA & HCPA & HCSA & HPS & LW & Total $(\%)$ \\
\hline Urine & $\mathbf{1 2 5}$ & $\mathbf{1 8 1}$ & $\mathbf{1 2}$ & $\mathbf{2}$ & - & $\mathbf{3 2 0}(\mathbf{7 0 . 3})$ \\
Secretions & 51 & 35 & 1 & 6 & 1 & $94(20.7)$ \\
Blood & $\mathbf{6}$ & $\mathbf{4}$ & $\mathbf{1}$ & - & $\mathbf{1}$ & $\mathbf{1 2}(\mathbf{2 . 6})$ \\
Catheter & 10 & 1 & - & - & - & $11(2.4)$ \\
Other & 9 & 27 & - & 2 & - & $18(4.0)$ \\
\hline Total & $\mathbf{2 0 1}$ & $\mathbf{2 2 8}$ & $\mathbf{1 4}$ & $\mathbf{1 0}$ & $\mathbf{2}$ & $\mathbf{4 5 5}(\mathbf{1 0 0})$ \\
\hline
\end{tabular}

${ }^{1}$ ISCMPA, Irmandade Santa Casa de Misericórdia de Porto Alegre; HCPA, Hospital de Clínicas de Porto Alegre; HCSA, Hospital da Criança Santo Antônio; HPS, Hospital de Pronto Socorro de Porto Alegre; LW, Laboratório Weinmann;

${ }^{2}$ Wounds, abdominal, oropharynx, and other secretions and body fluids.

most frequent sources of isolation. This is in agreement with literature reports, which point to E. faecalis as the main species involved in human infections, followed by E. faecium (20-21,2324). The prevalence of $E$. faecalis as the etiological agent of enterococcal infections appears to be associated with a greater potential virulence of the microorganisms of this species as compared to $E$. faecium, a species more related to antimicrobial resistance (14). The Irmandade Santa Casa de Misericórdia de Porto Alegre (ISCMPA) and Hospital de Clínicas de Porto Alegre (HCPA) were the institutions which provided the greatest number of isolates for this study, and a greater number of $E$. faecium isolates was obtained in the HCPA $(n=10)$ than in the other hospitals. E. faecium strain arouses more attention owing to its unique characteristics of antimicrobial resistance (35), something which was also found in this study.

Although the other enterococcal species of physiological groups I and II identified in this study (E. avium, E. casseliflavus, E. gallinarum e E. raffinosus) are less frequently

Table 3. Distribution of Enterococcus species according to isolation source, in 5 healthcare institutions in the city of Porto Alegre, Brazil.

Species

Isolation source E. faecalis E.faecium E. gallinarum E. avium E. casseliflavus E. durans E. hirae E. raffinosus Total

\begin{tabular}{crrrrrrrrr}
\hline Urine & 310 & 8 & - & - & - & 1 & 1 & - & 320 \\
Secretions & 83 & 2 & 2 & 5 & - & - & 2 & - & 94 \\
Blood & 11 & - & - & - & - & - & - & 1 & 12 \\
Catheter & 10 & - & 1 & - & - & - & - & - & 11 \\
Other & 8 & 3 & 4 & - & 2 & 1 & - & - & 18 \\
\hline Total & 422 & 13 & 7 & 5 & 2 & 2 & 3 & 1 & 455 \\
\hline
\end{tabular}


Table 4. Antimicrobial susceptibility among Enterococcus isolates from patients in 5 healthcare institutions in the city of Porto Alegre, Brazil.

\begin{tabular}{|c|c|c|c|c|c|c|c|c|c|}
\hline \multirow[b]{3}{*}{ Antimicrobial Agent } & \multicolumn{9}{|c|}{ Number of isolates $(\%)$} \\
\hline & \multicolumn{3}{|c|}{$\begin{array}{l}\text { All institutions } \\
(\mathrm{n}=455)\end{array}$} & \multicolumn{3}{|c|}{$\begin{array}{l}\text { ISCMPA }^{b} \\
(n=201)\end{array}$} & \multicolumn{3}{|c|}{$\begin{array}{l}\mathrm{HCPA}^{\mathrm{c}} \\
(\mathrm{n}=228)\end{array}$} \\
\hline & $\mathrm{S}^{\mathrm{a}}$ & $\mathrm{I}^{\mathrm{a}}$ & $\mathrm{R}^{\mathrm{a}}$ & $\mathrm{S}^{\mathrm{a}}$ & $\mathrm{I}^{\mathrm{a}}$ & $\mathrm{R}^{\mathrm{a}}$ & $S^{a}$ & $\mathrm{I}^{\mathrm{a}}$ & $\mathrm{R}^{\mathrm{a}}$ \\
\hline Ampicillin & $439(96.5)$ & 0 & $16(3.5)$ & $196(97.5)$ & 0 & $5(2.5)$ & $219(96.0)$ & 0 & $9(4.0)$ \\
\hline Ciprofloxacin & $205(45.0)$ & $147(32.3)$ & $103(22.6)$ & $110(54.7)$ & $31(15.4)$ & $60(29.9)$ & $80(35.1)$ & $107(46.9)$ & $41(18.0)$ \\
\hline Chloramphenicol & $291(64.0)$ & $51(11.2)$ & $113(24.8)$ & $110(54.7)$ & $29(14.4)$ & $62(30.9)$ & $157(68.9)$ & $20(8.8)$ & $51(22.4)$ \\
\hline Erythromycin & $201(44.2)$ & $60(13.2)$ & $194(42.6)$ & $81(40.3)$ & $19(9.5)$ & $101(50.3)$ & $109(47.8)$ & $32(14.0)$ & $87(38.2)$ \\
\hline Nitrofurantoin & $431(94.7)$ & $8(1.8)$ & $16(3.5)$ & $192(95.5)$ & $2(1.0)$ & $7(3.5)$ & $215(94.3)$ & $5(2.2)$ & $8(3.5)$ \\
\hline Norfloxacin & $304(66.8)$ & $51(11.2)$ & $100(22.0)$ & $127(63.2)$ & $19(9.5)$ & $55(27.4)$ & $156(68.4)$ & $29(12.7)$ & $43(18.9)$ \\
\hline Tetracycline & $143(31.4)$ & $30(6.6)$ & $282(62.0)$ & $60(29.9)$ & $18(9.0)$ & $123(61.2)$ & $67(29.4)$ & $10(4.4)$ & $151(66.2)$ \\
\hline Streptomycin & $379(83.3)$ & $11(2.4)$ & $65(14.3)$ & $168(83.6)$ & $6(3.0)$ & $27(13.4)$ & $185(81.1)$ & $5(2.2)$ & $38(16.7)$ \\
\hline Gentamicin & $143(31.4)$ & $3(0.7)$ & $107(23.5)$ & $138(68.7)$ & $2(1.0)$ & $61(30.4)$ & $184(80.7)$ & $1(0.4)$ & $43(18.9)$ \\
\hline Vancomycin & $435(95.6)$ & $20(4.4)$ & $0(0.0)$ & $197(98.0)$ & $4(2.0)$ & 0 & $218(95.6)$ & $10(4.4)$ & 0 \\
\hline
\end{tabular}

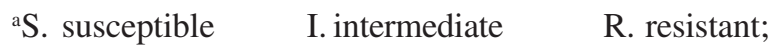

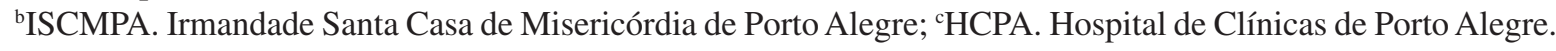

isolated, they have been also reported as etiological agents of infections in humans $(10,15,27)$.

Two species of the so-called physiological group III were isolated: E. hirae and E. durans, with 3 and 2 samples, respectively. These species, although occasionally isolated from clinical specimens of human origin $(8-10,19)$, are more often associated with infections in animals (5). The documentation of enterococcal infections caused by infrequent species, as well as the possibility of involvement of other species whose association with human pathology was unknown (13), calls attention to the fact that, increasingly, the laboratories of clinical microbiology must be attentive and updated with regard to the use of procedures which allow an accurate identification.

In this study we have assessed antimicrobial susceptibility through the agar diffusion test. The results indicate that $62.0 \%$ and $42.6 \%$ of the isolates were resistant to tetracycline ant erythromycin, respectively, which is in agreement with results obtained in a few international studies $(8,18)$. Similar data were obtained in previous works carried out in Brazil, in which resistance to erythromycin was found to be $41 \%$ (32). The high percentage of isolates resistant to tetracycline (54\%) was slightly higher than the one obtained by Mendonça (19), in studying isolates from 4 health institutions in the city of Rio de Janeiro. The results for chloramphenicol, with $24.8 \%$ of resistant isolates, were similar to those reported by other authors which described a resistance percentage of $20-42 \%(24,30)$. These data, when compared to the study by Atkison et al. (1) with enterococci isolated in the 1950s, illustrate the growing increase resistance among these microorganisms, since these authors found resistance of $0.9 \%$ to chloramphenicol, $2.7 \%$ to erythromycin, and $54 \%$ to tetracycline. The comparison of the data obtained in the two main hospitals participating in this study revealed that isolates isolated in the ISCMPA showed higher resistance levels to several antimicrobials than those isolated in the HCPA.

Ciprofloxacin is successfully used in the treatment of urinary tract infections (24). In the present study, the percentages of resistance obtained for the two fluoroquinolones tested, ciprofloxacin and norfloxacin, were similar, encompassing about $22 \%$ of the isolates. These percentages are also similar to those found by Giglio et al. (8) in Chile. On the other hand, Guirguitzova et al. (12) found a low percentage of resistance to ciprofloxacin (3\%) when investigating isolates in Bulgaria. The resistance to fluoroquinolones is related to mutations in gene gyrA, which codes for subunit A of DNA gyrase, and its detection occurred in the early 1990s, with the observation, then, of a rapid dissemination and significant increase of resistance among enterococci (33). The resistance to ciprofloxacin has been associated with high level of resistance to gentamicin (HLR-Ge) $(33,34)$. The association of this phenotype of resistance was also detected in the present study, since about $63.2 \%$ of the isolates presenting HLR-Ge were resistant to ciprofloxacin too. The levels of resistance to fluoroquinolones among the isolates isolated in the two main hospitals investigated here were variable, being higher among those obtained in the ISCMPA (29.9\% for ciprofloxacin; $27.4 \%$ for norfloxacin) than among those obtained in the HCPA (18.0\% for ciprofloxacin; 18.9\% for norfloxacin).

The susceptibility data obtained for nitrofurantoin were consistent with those of the literature, where resistance 
percentages of $4.1 \%$ are reported. The low proportion of nitrofurantoin-resistant isolates supports the indication by Murray (24) that the use of this antimicrobial can be effective in the treatment of uncomplicated urinary infections.

Resistance to ampicillin was observed in $16(3.5 \%)$ isolates, of which 8 were identified as E. faecalis, 7 as E. faecium, and one as E. raffinosus. A very similar percentage (2.8\%) was found in a study performed in the city of Niterói, RJ (20). Cereda et al. (3), studying isolates in the city of São Paulo, found a slightly higher percentage $(4.4 \%)$ and this resistance prevailed in $E$. faecium. Literature data indicate that $E$. faecium is the species most often associated with this type of resistance (28). Mendonça (19) studied isolates isolated in the city of Rio de Janeiro and found ampicillin resistance in these three species too.

The detection of HLR-A revealed significant percentages among isolates isolated in Porto Alegre. The percentages of HLR-Ge and HLR for streptomycin (HLR-St) were of $23.5 \%$ and $14.3 \%$, respectively, and of $2.8 \%$ for both antimicrobials. Giglio et al. (8) detected HLR-St in $57.6 \%$ of the isolates and HLR-Ge in $29.2 \%$. These percentages are higher than those found in the present work, yet close to those obtained by Guirguitzova et al. (12) for HLR-St (46\%) and HLR-Ge (42\%). Nevertheless, Gordon et al. (11) and Ma et al. (18) obtained percentages of HLR-Ge of $22.1 \%$ and $22.3 \%$, respectively, which are closer to those we obtained. Caballero-Granado et al. (2), in analyzing isolates isolated in several hospitals in Spain, detected the occurrence of HLR-Ge in $33 \%$ of enterococci recovered from patients with bacteremia. On the other hand, Mendonça (19) analyzed isolates isolated in the city of Rio de Janeiro and found HLR-St in 31.1\% of them and HLR-Ge in 24.9\%, while Mondino et al. (20) obtained percentages of $36.4 \%$ for HLR-Ge and $30.4 \%$ for HLR-St. Cereda et al. (3) obtained results similar to those reported here among isolates isolated in São Paulo, where 26.4\% of isolates presented HLR-Ge and $24.8 \%$ presented HLR-St. The comparison of the results obtained in the two most representative institutions of this study reveals that the percentage of HLR-Ge was higher among isolates of the ISCMPA (30.4\%) than among those of the HCPA (18.9\%). The data obtained in the different studies show that resistance percentages can vary according to geographical regions and institutions. Such variations can be explained by the ability to disseminate genetic elements (plasmids and transposons) coding for the modifying enzymes of aminoglycosides, as well as by the selective pressure that the use of particular antimicrobials exert on the microbial population of each institution and each location (4). Concerning the behavior of the various species, most of the isolates with HLR-A belonged to E. faecalis, which is in agreement with other studies carried out in Brazil $(19,20,31)$ and abroad $(2,10)$. This indicates that $E$. faecalis isolates expressing HLR-A stand as major etiological agents of enterococcal infections in our community. It is worth highlighting that HLR-Ge was detected in 5 isolates of $E$. faecium and in one of E. avium.
No isolate producing $\beta$-lactamase or with full resistance to vancomycin was detected in this study. Intermediate results were obtained in 20 isolates, including those belonging to species traditionally associated with intrinsic resistance to vancomycin ( 7 of E. gallinarum and 2 of E. casseliflavus) and the remainder belonging to $E$. faecalis.

It should be highlighted that the prevalence of resistance to some antimicrobials was not uniform between the two institutions which contributed with the greater number of isolates. If intermediate isolates are grouped in the resistant category, resistance in the ISCMPA was higher than in the HCPA for chloramphenicol $(45.2 \%$ versus $31.1 \%, \mathrm{P}=0.002)$ and gentamicin (31.3\% versus $19.2 \%, \mathrm{P}=0.004)$. For ciprofloxacin, however, resistance was higher in the HCPA (64.9\% versus $45.3 \%, \mathrm{P}=0.0004)$. These findings may reflect differences in the standards of antimicrobial prescription in these institutions. We emphasize, however, that our results refer to isolates obtained in the 1996-1997 period, and may not reflect the present scenario in the city of Porto Alegre.

\section{RESUMO}

\section{Sensibilidade aos antimicrobianos entre amostras de Enterococcus isolados na cidade de Porto Alegre, RS, Brasil}

A resistência a várias classes de agentes antimicrobianos é uma característica marcante dos enterococos observada em diferentes regiões geográficas. Informações sobre amostras isoladas na região sul do Brasil ainda são limitadas. No presente estudo, 455 enterococos isolados consecutivamente de pacientes moradores na cidade de Porto Alegre, Brasil, foram identificados ao nível de espécie e testados em relação a sua sensibilidade aos antimicrobianos através de testes de difusão em agar. As espécies mais freqüentes foram $E$. faecalis $(92,8 \%)$, seguidas por $E$. faecium (2,9\%), E. gallinarum (1,5\%), E. avium $(1,1 \%)$, E. hirae $(0,7 \%), E$. casseliflavus $(0,4 \%)$, E. durans $(0,4 \%)$ e E. raffinosus $(0,2 \%)$. Os testes de sensibilidade revelaram que $62,0 \%$ das amostras foram resistentes à tetraciclina, $42,6 \%$ à eritromicina, $24,8 \%$ ao cloranfenicol, 22,6\% à ciprofloxacina, 22,0\% à norfloxacina, 3,5\% à ampicilina e 3,5\% á nitrofurantoína. Resistência a níveis elevados de aminoglicosídeos foi encontrada em 37,8\% das amostras, com $23,5 \%$ sendo resistente à gentamicina, $14,3 \%$ à estreptomicina e $2,8 \%$ a ambos gentamicina e estreptomicina. Nenhuma amostra com resistência adquirida à vancomicina ou produtora de $\beta$ lactamase foi encontrada. Os resultados indicam um significante percentual de amostras resistentes a diferentes antimicrobianos, apontando a necessidade de estratégias de controle para evitar a disseminação de cepas resistentes e de vigilância contínua para a detecção de características emergentes de resistência.

Palavras-chave: Enterococcus, teste de sensibilidade, resistência 


\section{REFERENCES}

1. Atkinson, B.A.; Abu-Al-Jabait, A.; Leblanc, D.J. Antibiotic resistance among enterococci isolated from clinical specimens between 1953 and 1954. Antimicrob. Agents Chemother, 41:1598-1600, 1997.

2. Caballero-Granado, F.J.; Cisneros, J.M.; Luque, R.; Torres-Tortosa, M.; Gamboa, F.; Diez, F.; Villanueva, J.L.; Pérez-Cano, R.; Pasquau, J.; Merino, D.; Menchero, A.; Mora, D.; López-Ruz, M.A.; Vergara, A. Comparative study of bacteremias caused by Enterococcus spp. with and without high-level resistance to gentamicin. J. Clin. Microbiol., 36:520-525, 1998.

3. Cereda, R.; Pignatari, A.C.; Hashimoto, A.; Sader, H. In vitro antimicrobial activity against enterococci isolated in a university hospital in São Paulo, Brazil. Braz. J. Infect. Dis., 1:83-90, 1997.

4. Davis, J.; Wright, G.D. Bacterial resistance to aminoglycoside antibiotics. Trends Microbiol., 5:234-240, 1997.

5. Espinola, M. Estudo sobre a diversidade fenotípica e genotípica de Enterococos do grupo fisiológico III de origem humana e animal. Rio de Janeiro, 1999. (Tese de Mestrado. Instituto de Microbiologia, UFRJ.)

6. Facklam, R.R.; Sahm, D.F; Teixeira, L.M. Enterococcus. In: Manual of Clinical Microbiology. P.R. Murray, E.J. Baron, M.A. Pfaller, F.C. Tenover \& R.H. Yolken (eds). $7^{\text {th }}$ ed., ASM Press, Washington, D.C, 1999, p.297-305.

7. Frieden, T.R.; Munsiff, S.S.; Low, D.E.; Willey, B.M.; Williams, G.; Faur,Y.; Eisner,W.; Warren, S. \& Kreiswirth, B. Emergence of vancomycin-resistant enterococci in New York city. Lancet., 342:7679, 1993.

8. Giglio, M.S.M.; Pinto, M.E.C.; Córdova, E.J.; Escandar, P.D.; Waman, C.M. Identificación de especies de Enterococcus en muestras clínicas y susceptibilidad a agentes antimicrobianos. Rev. Méd. Chile, 124:7076, 1996.

9. Gilad, J.; Borer, A.; Riesenberg, K.; Peled, N.; Shnaider, A.; Schlaeffer, F. Enterococcus hirae septicemia in a patient with end-stage renal disease undergoing hemodialysis. Eur. J. Clin. Microbiol. Infect. Dis., 17:576-577, 1998.

10. Gordon, S.; Swenson, J.M.; Hill, B.C.; Pigott, N.E.; Facklam, R.R.; Cooksey, R.C.; Thornsberry, C.; Group, E.S.; Jarvis, W.R.; Tenover, F.C. Antimicrobial susceptibility patterns of common and unusual species of enterococci causing infections in the United States. $J$. Clin. Microbiol., 30:2373-2378, 1992.

11. Gray, J.W.; Pedler, S.J. Antibiotic-resistant enterococci. J. Hosp. Infect., 21:1-14, 1992.

12. Guirguitzova, B.; Chankova, D.; Zozikov, B.; Minkov, N. Les entérocoques comme uropathogènes. Fréquence d'isolement et sensibilité envers les substances antibactériennes. Ann. Urol., 32:15-19, 1998.

13. Hsueh, P.; Teng, L.; Chen, Y.; Yang, P.; Ho, S.; Luh, K. Recurrent bacteremic peritonitis caused by Enterococcus cecorum in a patient with liver cirrhosis. J. Clin. Microbiol., 38:2450-2452, 2000.

14. Huycke, M.M.; Sahm, D.F.; Gilmore, M.S. Multiple-drug resistant enterococci: the nature of the problem and an agenda for the future. Emerg. Infect. Dis., 4:239-249, 1998.

15. Kurup, A. Tee, W.S.N.; Loo, L.H.; Lin, R. Infection of central nervous system by motile Enterococcus: first case report. J. Clin. Microbiol., 39:820-822, 2001.

16. Leclercq, R.; Derlot, E.; Duval, J.; Courvalin, P. Plasmid-mediated resistance to vancomycin and teicoplanin in Enterococcus faecium. N. Eng. J. Med., 319:157-161, 1988.

17. Leclercq, R.; Dutka-Malen, S.; Brisson-Noël, A.; Molinas, C.; Derlot, E.; Arthur, M.; Duval, J.; Courvalin, P. Resistance of enterococci to aminoglycosides and glycopeptides. Clin. Infect. Dis., 15:495-501, 1992.

18. Ma, X.; Kudo, M.; Takahashi, A.; Tanimoto, K.; Ike, Y. Evidence of nosocomial infection in Japan caused by high-level gentamicin- resistant Enterococcus faecalis and identification of the pheromoneresponsive conjugative plasmid encoding gentamicin resistance. $J$. Clin. Microbiol., 36:2460-2464, 1998.

19. Mendonça, C.R.V. Ocorrência e diversidade genética de enterococos, apresentando resistência a níveis elevados de antimicrobianos, isolados em quatro instituições de saúde na cidade do Rio de Janeiro, 1998. (Tese de Mestrado. Instituto de Microbiologia, UFRJ.)

20. Mondino, S.S.B.; Castro, A.C.D.; Mondino, P.J.J.; Carvalho, M.G.S.; Silva, K.M.F.; Teixeira, L.M. Phenotypic and genotypic characterization of clinical and intestinal enterococci isolated from inpatients and outpatients in two Brazilian hospitals. Microb. Drugs Res., 9(2):167-174, 2003.

21. Moellering Jr., R.C. The Enterococcus: a classic example of the impact of antimicrobial resistance on therapeutic options. $J$. Antimicrob. Chemother, 28:1-12, 1992.

22. Mundy, L.M.; Sahm, D.F.; Gilmore, M. Relationships between enterococcal virulence and antimicrobial resistance. Clin. Microbiol. Rev. 13:513-522, 2000.

23. Mutnick, A.H.; Biedenbach, D.J.; Jones, R.N. Geographic variations and trends in antimicrobial resistance among Enterococcus faecalis and Enterococcus faecium in the SENTRY antimicrobial surveillance program (1997-2000). Diagn. Microbiol. Infect. Dis., 46:63-68, 200.3

24. Murray, B.E. The life and times of the Enterococcus. Clin. Microbiol. Rev., 3:46-65, 1990.

25. Murray, B.E. Diversity among multidrug-resistant enterococci. Emerging Infectious Dis., 4:37-47, 1998.

26. National Committee for Clinical Laboratory Standards. Performance standards for antimicrobial disk susceptibility tests. Approved Standard, Seventh edition. NCCLS document M2-A7. National Committee for Clinical Laboratory Standards, Villanova, Wayne, PA, 2000.

27. Pangon, B.; Pina, P.; Gazagne, L.; Chauvel, M.; Godard, T.; Courvalin, P.; Allouch, P. \& Collége de Bactériologie, Virologie, Hygiene des Hóspitaux. Antimicrobial susceptibility of 471 enterococcal strains responsible for infections at 101 French hospitals. Eur. J. Microbiol. Infect. Dis., 18:836-838, 1999.

28. Sapico, F.L.; Canawati, H.N.; Girunas, V.J.; Gilmoe, D.S.; Montgomerie, J.Z.; Tuddenham, W.J.; Facklam, R.R. Enterococci highly resistant to penicillin and ampicillin: na emerging clinical problem? J. Clin. Microbiol., 27:2091-2095, 1989.

29. Schaberg, D.R.; Culver, D.H.; Gaynes, R.A. Major trends in the microbial etiology of nosocomial infections. Am. J. Med. 91(Suppl.3B):72S-75S, 1991.

30. Stern, C.S. Estudo de marcadores biológicos e epidemiológicos de microrganismos do gênero Enterococcus. Rio de Janeiro, 1993. (Ph.D. Thesis. UFRJ, RJ, Brasil).

31. Stern, C.S.; Carvalho, M.G.S.; Teixeira, L.M. Characterization of enterococci isolated from human and nonhuman sources in Brazil. Diagn. Microbiol. Infect. Dis., 20:61-67, 1994.

32. Stuckert, A.P.A.L. Caracterização fenotípica e pesquisa de marcadores de resistência a antimicrobianos entre Enterococcus isolados de espécimens clínicos e de microbiota intestinal. Rio de Janeiro, 1994. (Tese de mestrado, Instituto de Microbiologia, UFRJ).

33. Tankovic, J.; Mahjoubi, F.; Courvalin, P.; Duval, J.; Leclercq, R. Development of fluoroquinolone resistance in Enterococcus faecalis and role of mutations in the DNA gyrase gyrA gene. Antimicrob. Agents Chemother., 40:2558-2561, 1996.

34. Vandamme, P.; Vercauteren, E.; Lammens, C.; Pensart, N.; Leven, M.; Pot, B., Leclercq, R.; Goossens, H. Survey of enterococcal susceptibility patterns in Belgium. J. Clin. Microbiol., 34:2572-2576, 1996.

35. Wade, J.J. Enterococcus faecium in hospitals. Eur. J. Clin. Microbiol. Infect. Dis., 16:113-119, 1997. 